\title{
Characterization of a Novel Metal-Dependent D-Psicose 3-Epimerase from Clostridium scindens 35704
}

\author{
Wenli Zhang ${ }^{1}$, Dan Fang ${ }^{1}$, Qingchao Xing ${ }^{1}$, Leon Zhou ${ }^{1,2}$, Bo Jiang ${ }^{1}$, Wanmeng Mu $^{1 *}$
}

1 State Key Laboratory of Food Science and Technology, Jiangnan University, Wuxi, People's Republic of China, 2 Roquette America, Keokuk, lowa, United States of America

\begin{abstract}
The noncharacterized protein CLOSCI_02528 from Clostridium scindens ATCC 35704 was characterized as D-psicose 3epimerase. The enzyme showed maximum activity at $\mathrm{pH} 7.5$ and $60^{\circ} \mathrm{C}$. The half-life of the enzyme at $50^{\circ} \mathrm{C}$ was 108 min, suggesting the enzyme was relatively thermostable. It was strictly metal-dependent and required $\mathrm{Mn}^{2+}$ as optimum cofactor for activity. In addition, $\mathrm{Mn}^{2+}$ improved the structural stability during both heat- and urea-induced unfolding. Using circular dichroism measurements, the apparent melting temperature $\left(T_{\mathrm{m}}\right)$ and the urea midtransition concentration $\left(C_{\mathrm{m}}\right)$ of metalfree enzyme were $64.4^{\circ} \mathrm{C}$ and $2.68 \mathrm{M}$. By comparison, the $\mathrm{Mn}^{2+}$-bound enzyme showed higher $T_{\mathrm{m}}$ and $C_{\mathrm{m}}$ with $67.3^{\circ} \mathrm{C}$ and $5.09 \mathrm{M}$. The Michaelis-Menten constant $\left(K_{\mathrm{m}}\right)$, turnover number $\left(k_{\text {cat }}\right)$, and catalytic efficiency $\left(k_{\text {cat }} / K_{\mathrm{m}}\right)$ values for substrate Dpsicose were estimated to be $28.3 \mathrm{mM}, 1826.8 \mathrm{~s}^{-1}$, and $64.5 \mathrm{mM}^{-1} \mathrm{~s}^{-1}$, respectively. The enzyme could effectively produce D-psicose from D-fructose with the turnover ratio of $28 \%$.
\end{abstract}

Citation: Zhang W, Fang D, Xing Q, Zhou L, Jiang B, et al. (2013) Characterization of a Novel Metal-Dependent D-Psicose 3-Epimerase from Clostridium scindens 35704. PLoS ONE 8(4): e62987. doi:10.1371/journal.pone.0062987

Editor: Vladimir N. Uversky, University of South Florida College of Medicine, United States of America

Received January 23, 2013; Accepted March 27, 2013; Published April 30, 2013

Copyright: (c) 2013 Zhang et al. This is an open-access article distributed under the terms of the Creative Commons Attribution License, which permits unrestricted use, distribution, and reproduction in any medium, provided the original author and source are credited.

Funding: This work was supported by the NSFC Project (No. 31171705 and 21276001), the 973 Project (No. 2012CB720802), the 863 Project (No. 2011AA100904), the Fundamental Research Funds for the Central Universities (No. JUSRP51304A), and the Support Project of Jiangsu Province (No. BE2011622, BE2011766, BE2010678, and BE2010626). The funders had no role in study design, data collection and analysis, decision to publish, or preparation of the manuscript.

Competing Interests: The authors have read the journal's policy and have the following conflicts: Leon Zhou is an employee of Roquette America. There are no patents, products in development or marketed products to declare. This does not alter the authors' adherence to all the PLOS ONE policies on sharing data and materials, as detailed online in the guide for authors.

*E-mail: wmmu@jiangnan.edu.cn

\section{Introduction}

D-Psicose (D-ribo-2-hexulose or D-allulose), the C3 epimer compound of D-fructose, is considered as a kind of rare sugar, which was defined by the International Society of Rare Sugars (ISIR) as monosaccharides and their derivatives existing in nature in extremely small quantities (The $1^{\text {st }}$ International Symposium of ISRS, Takamatsu, Japan, 2002). It has $70 \%$ relative sweetness but only $0.3 \%$ energy of sucrose [1], and is suggested as an ideal sucrose substitute for food products [2]. It has important physiological functions, such as blood glucose suppressive effect $[3,4]$, reactive oxygen species scavenging activity [5,6], and neuroprotective effect [7]. In addition, it can improve the gelling behavior and produces good flavor during food process $[8,9]$. Importantly, it has been approved as "generally regarded as safe" (GRAS) by Food and Drug Administration (FDA) in Jun. 2012 (GRN No. 400), and has been allowed to be used as ingredient in a range of foods and dietary supplements. Commercial bioproduction of D-psicose may be realized through epimerization from Dfructose using D-tagatose 3-epimerase (DTEase) family enzymes, which have recently attracted attention of many researchers by its importance in application of rare sugar bioproduction [2].

Although the genes of DTEase family enzymes are widely predicted in various microorganisms, only a few of the enzymes have been conclusively characterized and identified through experimental evidence. Twenty years ago, DTEase was firstly characterized by Izumori et al. from Pseudomonas cichorii, showing C-3 epimerization activity of ketohexoses with the optimum substrate of D-tagatose [10]. Also, the P. cichorii DTEase was successfully used in D-psicose mass bioproduction [11,12]. In 2006, the second enzyme with C-3 epimerization activity of ketohexoses was identified from Agrobacterium tumefaciens, and it was named D-psicose 3-epimerase (DPEase), due to its high substrate specificity for D-psicose [13]. Recently, another three DTEase family enzymes were characterized from Rhodobacter sphaeroides SK011 (DTEase) [14], Clostridium cellulolyticum H10 (DPEase) [15], and Ruminococcus sp. 5_1_39BFAA (DPEase) [16], respectively.

The crystal structures of $A$. tumefaciens DPEase [17], P. cichorii DTEase [18], and C. cellulolyticum DPEase [19] have been identified. All the enzymes assemble into a tetramer and the subunits have around 295 amino acid residues with the molecular weight of approximately $32 \mathrm{kDa}$. They show the similar $(\beta / \alpha)_{8}$ TIM barrel structure and display a divalent metal coordinating site in the enzyme's active center. Through multiple sequence alignment of reported DTEase family enzymes, they show relatively low similarity (20-60\% identity) of amino acid sequence, but the amino acid residues responsible for metal coordination are strictly conserved in all the enzymes, suggesting that the divalent metal ion is possibly important to the structure and function of the enzyme as the cofactor. Interestingly, the abovementioned DTEase family enzymes show different requirement for metal cofactor to the activity and stability of the enzyme. P. cichorii DTEase does not require any cofactor for its activity, and even loses activity under some metal ions [20]. R. sphaeroides DTEase [14], A. tumefaciens DPEase [13], and Ruminococcus sp. DPEase [16] 
can display activity without metal ion, but their activity is remarkably enhanced by metal ions especially $\mathrm{Mn}^{2+}$. However, C. cellulolyticum DPEase is strictly metal-dependent and does not show activity in absence of metal ions [15]. C. cellulolyticum DPEase requires metal ion as essential cofactor to display activity and shows the maximal activity in the presence of $\mathrm{Co}^{2+}$. In addition, the $\mathrm{Co}^{2+}$ can significantly improve the thermostability of $C$. cellulolyticum DPEase [15].

In this study, the gene encoding the hypothetical protein CLOSCI_02528 with protein ID ZP_02432283 from the Clostridium scindens ATCC 35704 was cloned and overexpressed in E. coli. The hypothetical protein CLOSCI_02528 was identified as a new member of DTEase family enzymes. The enzyme was strictly metal-dependent like C. cellulolyticum DPEase, and its optimum substrate was D-psicose. The enzyme properties and kinetic parameters were determined, and compared to those of other DTEase family enzymes. Especially, the effect of metal ion on the activity and stability of the enzyme was studied in detail.

\section{Materials and Methods}

\section{Chemicals and Reagents}

The resin for protein purification, the Chelating Sepharose Fast Flow, was obtained from GE (Uppsala, Sweden). The pET$22 \mathrm{~b}(+)$ expression vector was obtained from Novagen (Darm-
(A)

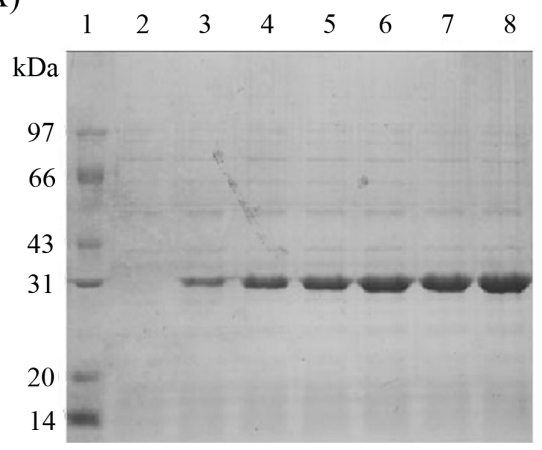

(B)

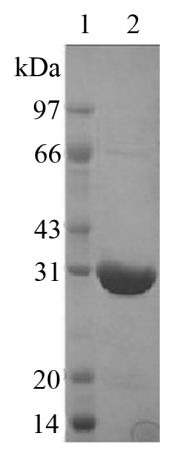

Figure 2. SDS-PAGE analysis of proteins stained with Coomassie blue. A represented the SDS-PAGE of whole-cell protein. Lane 1, protein marker; lane 2, the cell without IPTG induction; and lane 3-8, the cell induced by IPTG for 1-6 h. B showed the SDS-PAGE analysis of the purified recombinant $C$. scindens DPEase (lane 2). doi:10.1371/journal.pone.0062987.g002

stadt, Germany). Electrophoresis reagents were purchased from Bio-Rad. Isopropyl $\beta$-D-1-thiogalactopyranoside (IPTG) and all chemicals used for enzyme assays and characterization were at least of analytical grade obtained from Sigma (St Louis, MO, USA) and Sinopharm Chemical Reagent (Shanghai, China).

Csc-DPEase

Cce-DPEase

Rsp-DPEase

Pci-DTEase

Atu-DPEase

Rsp-DTEase

Csc-DPEase

Cce-DPEase

Rsp-DPEase

Pci-DTEase

Atu-DPEase

Rsp-DTEase

Csc-DPEase

Cce-DPEase

Rsp-DPEase

Pci-DTEase

Atu-DPEase

Rsp-DTEase

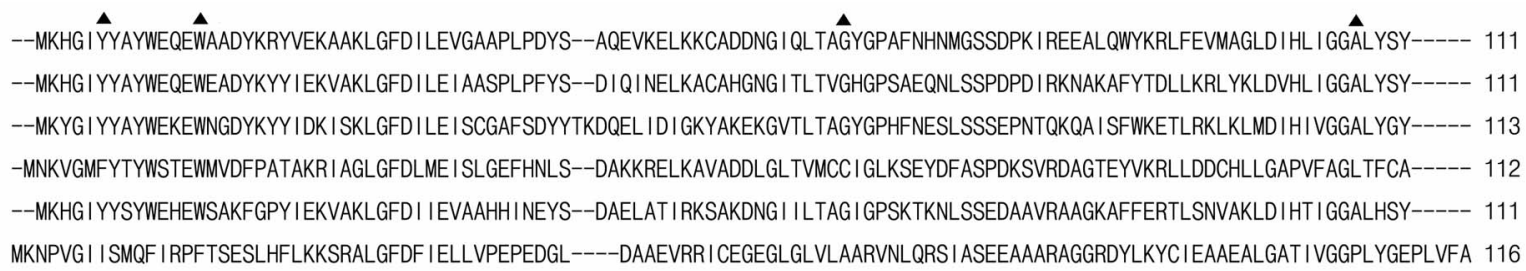
$\star$ :

WPVDFA-TANKEE-DWKHSVEGMQI LAP I ASQYG I NLGMEVLNRFÉSHI LNTSEEGVKFVTEVGMDNVKVMLDTFHMN IEESS I GDA I RHAGKLLGHFHTGECNRMVPGKGRTPWREI GD 229 WPIDYTKT I DKKG-DWERSVESVREVAKVAEACGVDFCLEVLNRFENYLINTAQEGVDFVKQVDHNNVKVMLDTFHMN I EEDSIGGA IRTAGSYLGHLHTGECNRKVPGRGR IPWVEIGE 230 WPVDYSKPFDKKR-DLENSI KNMKI I SQYAEEYDI MMGMEVLNRFEGYMLNTCDEALAYVEEVGSSNVGVMLDTFHMN I EEDN I AAA I RKAGDRLYHFHIGEGNRKVPGKGMLPWNEI GQ 232 WPQSPPLDMKDKRPYVDRA I ESVRRVI KVAEDYGI I YALEVVNRFEQWLCNDAKEA IAFADAVDSPACKVQLDTFHMNIEETSFRDAILACKGKMGHFHLGEANRLPPGEGRLPWDEIFG 232 WPIDYSQPVDKAG-DYARGVEG INGI ADFANDLGI INCIEVLNRFENHVLNTAAEGVAFVKDVGKNNVKVMLDTFHMNIEEDSFGDAIRTAGPLLGHFHTGESNRRVPGKGRMPWHEIGL 230 GRPPFPWTAEQ I ATRAARTVEGLAEVAPLAASAGKVFGLEPLNRFETDIVNTTAQA IEVVDAVGSPGLGVMLDTFHMNMEERSIPDAIRATGARLVHFQANENHRGFPGTGTMDWTAIAR 236

$$
\text { - } \Delta
$$

ALREIEYDGTVVMEPFVRMGGQVGSDIKVWRDISKGAGEDRLDEDARRAVEFQRYMLEWK---- 289

ALADI GYNGSVVMEPFVRMGGTVGSNI KVWRDISNGADEKMLDREAQAALDFSRYVLECHKHS- 293

ALRD I NYQHAAVMEPFVMQGGTVGHDI I I WRD I I GNCSEVTLDMDAQSALHFVKHVFEV----- 291

ALKEIGYDGT IVMEPFMRKGGSVSRAVGVWRDMSNGATDEEMDERARRSLQFVRDKLA------ 290

ALRDINYTGAVI MEPFVKTGGT IGSDIKVWRDLSGGADI AKMDEDARNALAFSRFVLGG----- 289

ALGQAGYAGPVSLEPFRRDDERVALPIAHWR-----APHEDEDEKLRAGLGLIRSAITLAEVTH 295

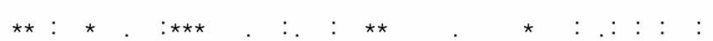

Figure 1. Multiple sequence alignment of DTEase family enzymes and their homologs. Amino acid sequence for DPEase from C. scindens 35704 (Csc-DPEase; GeneBank accession No: CLOSCI_02528) was aligned with C. cellulolyticum H10 (Cce-DPEase; ACL75304), Ruminococcus sp. 5 1 39BBAA (Rsp-DPEase; ZP 04858451), P. cichorii DTEase (Pci-DTEase; BAA24429), A. tumefaciens DPEase (Atu-DPEase; AAL45544), and R. sphaeroides DTEase (Rsp-DTEase; ACO59490). The alignment was performed using ClustalW2 program (http://www.ebi.ac.uk/Tools/clustalw2/index. $\mathrm{html}$ ). Amino acid residues that are identical in all the displayed sequences are marked by asterisks $\left(^{*}\right)$, strongly conserved or weakly conserved residues are indicated by colons (:) or dots (.), respectively. The symbol $\mathbf{\square}, \boldsymbol{\Theta}$, and $\boldsymbol{\Delta}$ represented the residues involved in the metal coordinating site, those responsible for the interaction between the enzyme and $\mathrm{O} 1, \mathrm{O} 2$, and $\mathrm{O} 3$ of $\mathrm{D}$-fructose, and those providing a hydrophobic environment around the substrate around the 04, O5, and 06 of D-fructose, respectively (according to the crystal structures of $C$. cellulolyticum DPEase, A. tumefaciens DPEase, and P. cichorii DTEase).

doi:10.1371/journal.pone.0062987.g001 

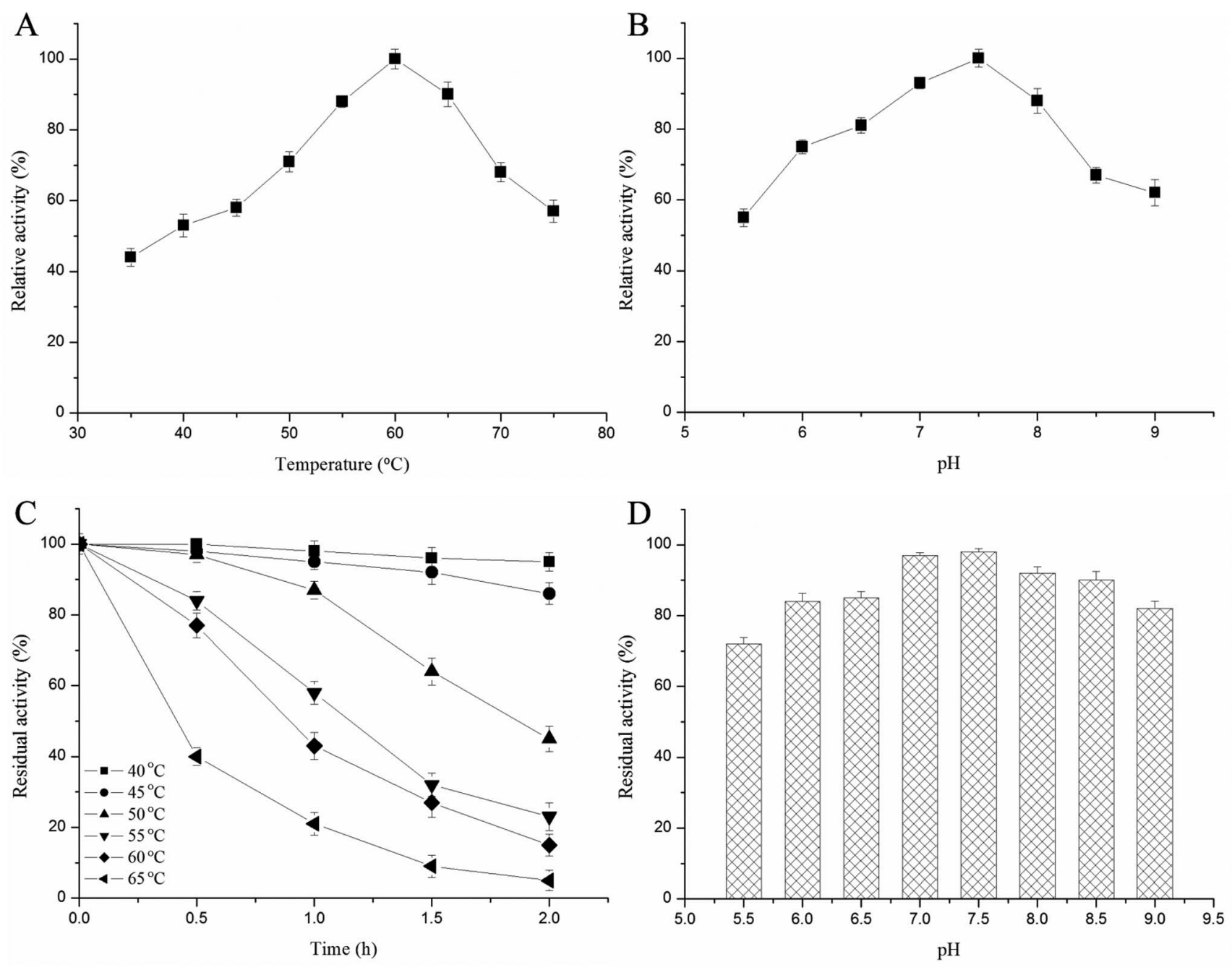

Figure 3. Enzymatic properties of $C$. scindens DPEase. Panel A and B showed the effect of $\mathrm{pH}$ and temperature on the activity of $C$. scindens DPEase. $C$ and $D$ represented the effect of temperature and $\mathrm{pH}$ on the stability of $C$. scindens DPEase. The thermal stability was investigated by exposing the enzyme at different temperature for different time intervals at $\mathrm{pH}$ 7.5. The $\mathrm{pH}$ stability was analyzed by pre-incubating the enzyme buffers of different $\mathrm{pH}$ values at $4^{\circ} \mathrm{C}$ for $2 \mathrm{~h}$ and measuring the remaining activity at $60^{\circ} \mathrm{C}$ and $\mathrm{pH} 7.5$. Values are means of three replications \pm standard deviation.

doi:10.1371/journal.pone.0062987.g003

\section{Gene Cloning and Protein Expression}

The full-length nucleotide sequence of the gene encoding the hypothetical protein CLOSCI_02528 from the C. scindens ATCG 35704 was synthesized and incorporated with $\mathcal{N} d e \mathrm{I}$ and $\mathrm{Xho}$ I sites in the $5^{\prime}$ - and $3^{\prime}$-terminal of the gene, respectively, and then cloned into pUC57 vector by Shinegene Molecular Biothnology Co., Ltd (Shanghai, China). Then the plasmid was sub-cloned into pET-22b(+) vector with $\mathcal{N} d e \mathrm{I}$ and $\mathrm{XhoI}$ sites, therefore, an in-frame fusion $6 \times$ histidine-tag sequence at the $\mathrm{C}$-terminus was provided in the reconstructed plasmid, named by pET-cs-dpe. And the pETcs-dpe was transformed into $E$. coli BL21(DE3).

The recombinant $E$. coli for protein expression was cultivated with shaking (200 rpm) in $400 \mathrm{ml}$ of LB medium containing $50 \mu \mathrm{g} / \mathrm{ml}$ ampicillin at $37^{\circ} \mathrm{C}$. When the $\mathrm{OD}_{600}$ reached 0.6 , IPTG was added at $0.5 \mathrm{mM}$, and DPEase was induced and overexpressed at $30^{\circ} \mathrm{C}$ for $6 \mathrm{~h}$, and harvested by centrifugation at $4^{\circ} \mathrm{C}$ for $10 \mathrm{~min}$ at $10,000 \mathrm{~g}$. The enzyme was expressed as $6 \times$ histidinetagged fusion protein, which was available for affinity chromatography.

\section{Protein Purification}

Four gram of wet cell pellets were resuspended in $20 \mathrm{~mL}$ of lysis buffer ( $50 \mathrm{mM}$ Tris-HCl, $100 \mathrm{mM} \mathrm{NaCl}, \mathrm{pH} 7.5)$ and disrupted by sonication at $4^{\circ} \mathrm{C}$ for $6 \mathrm{~min}$ (pulsations of $3 \mathrm{~s}$, amplify 90) using a Vibra-Cell ${ }^{\mathrm{TM}} 72405$ Sonicator. The lysate was centrifuged at $20,000 \mathrm{~g}$ for $30 \mathrm{~min}$ at $4^{\circ} \mathrm{C}$. Then, the $6 \times$ histidine-tagged fusion enzyme was purified by nickel-affinity chromatography (GE Healthcare) according to manufacturer's protocol (Instructions 71-5001-87 AE; GE Healthcare). The $15 \mathrm{~mL}$ of supernatant was loaded onto Chelating Sepharose Fast Flow resin column $(1.0 \mathrm{~cm} \times 10.0 \mathrm{~cm})$, previously chelating $\mathrm{NiSO}_{4}$ and equilibrated with a binding buffer $(50 \mathrm{mM}$ Tris$\mathrm{HCl}, 500 \mathrm{mM} \mathrm{NaCl}, \mathrm{pH}$ 7.5). After washing with the washing buffer $(50 \mathrm{mM}$ Tris-HCl, $500 \mathrm{mM} \mathrm{NaCl}, 50 \mathrm{mM}$ imidazole, $\mathrm{pH} 7.5)$ to remove unbound fractions, the DPEase was eluted from the column with an elution buffer $(50 \mathrm{mM} 50 \mathrm{mM}$ Tris$\mathrm{HCl}, 500 \mathrm{mM} \mathrm{NaCl}, 500 \mathrm{mM}$ imidazole, $\mathrm{pH}$ 7.5). The active fractions were pooled and dialyzed overnight against $50 \mathrm{mM}$ Tris-HCl buffer ( $\mathrm{pH} 7.5)$ containing $10 \mathrm{mM}$ ethylenediamine tetraacetic acid (EDTA) at $4^{\circ} \mathrm{C}$. Subsequently, the enzyme was 
Table 1. Comparison of biochemical properties and kinetic parameters of DTEase family enzymes.

\begin{tabular}{|c|c|c|c|c|c|c|}
\hline Strains & C. scindens ${ }^{a}$ & $\begin{array}{l}\text { C. cellulolyticum } \\
\text { [15] }\end{array}$ & $\begin{array}{l}\text { Ruminococcus sp. } \\
\text { [16] }\end{array}$ & $\begin{array}{l}\text { A. tumefaciens } \\
\text { [13] }\end{array}$ & $\begin{array}{l}\text { P. cichorii } \\
\text { [20] }\end{array}$ & $\begin{array}{l}\text { R. sphaeroides } \\
\text { [14] }\end{array}$ \\
\hline Optimum temperature $\left({ }^{\circ} \mathrm{C}\right)$ & 60 & 55 & 60 & 50 & 60 & 40 \\
\hline Optimal pH & 7.5 & 8.0 & $7.5-8.0$ & 8.0 & 7.5 & 9.0 \\
\hline Metal ion requied & $\mathrm{Mn}^{2+}$ & $\mathrm{Co}^{2+}$ & None & $\mathrm{Mn}^{2+}$ & None & $\mathrm{Mn}^{2+}$ \\
\hline Half-life at $50^{\circ} \mathrm{C}(\mathrm{min})$ & 108 & $>120$ & $>240$ & 63.5 & NR & Approximately 60 \\
\hline $\begin{array}{l}\text { Substrate with highest } \\
\text { specificity }\end{array}$ & D-Psicose & D-Psicose & D-Psicose & D-Psicose & D-Tagatose & D-Fructose \\
\hline$k_{\text {cat }}\left(\min ^{-1}\right)$ & $\begin{array}{l}1,827 \pm 136 \text { (D-Psicose) } \\
350 \pm 26 \text { (D-Fructose) } \\
44.2 \pm 3.8 \text { (D-Tagatose) }\end{array}$ & $\begin{array}{l}\text { 3,243.5 (D-Psicose) } \\
\text { 3,354.5 (D-Fructose) } \\
\text { 184.8 (D-Tagatose) }\end{array}$ & $\begin{array}{l}\text { 2,427 (D-Psicose) } \\
3,562 \text { (D-Fructose) } \\
109 \text { (D-Tagatose) }\end{array}$ & $\begin{array}{l}2381 \text { (D-Psicose) } \\
2068 \text { (D-Fructose) } \\
270 \text { (D-Tagatose) }\end{array}$ & $\mathrm{NR}^{b}$ & NR \\
\hline$K_{\mathrm{m}}(\mathrm{mM})$ & $\begin{array}{l}28.3 \pm 3.2 \text { (D-Psicose) } \\
40.1 \pm 2.5 \text { (D-Fructose) } \\
175.7 \pm 19.3 \text { (D-Tagatose) }\end{array}$ & $\begin{array}{l}17.4 \text { (D-Psicose) } \\
53.5 \text { (D-Fructose) } \\
244 \text { (D-Tagatose) }\end{array}$ & $\begin{array}{l}48 \text { (D-Psicose) } \\
216 \text { (D-Fructose) } \\
231 \text { (D-Tagatose) }\end{array}$ & $\begin{array}{l}12 \text { (D-Psicose) } \\
24 \text { (D-Fructose) } \\
762 \text { (D-Tagatose) }\end{array}$ & 55 (D-Tagatose) & NR \\
\hline $\begin{array}{l}k_{\mathrm{cat}} / K_{\mathrm{m}} \\
\left(\mathrm{mM}^{-1} \min ^{-1}\right)\end{array}$ & $\begin{array}{l}64.5 \pm 4.8 \text { (D-Psicose) } \\
8.72 \pm 0.63 \text { (D-Fructose) } \\
0.25 \pm 0.02 \text { (D-Tagatose) }\end{array}$ & $\begin{array}{l}186.4 \text { (D-Psicose) } \\
62.7 \text { (D-Fructose) } \\
0.75 \text { (D-Tagatose) }\end{array}$ & $\begin{array}{l}51 \text { (D-Psicose) } \\
16 \text { (D-Fructose) } \\
0.47 \text { (D-Tagatose) }\end{array}$ & $\begin{array}{l}205 \text { (D-Psicose) } \\
85 \text { (D-Fructose) } \\
0.35 \text { (D-Tagatose) }\end{array}$ & NR & NR \\
\hline $\begin{array}{l}\text { Equilibrium ratio between D- } \\
\text { psicose and D-fructose }\end{array}$ & $28: 72\left(50^{\circ} \mathrm{C}\right)$ & $32: 68\left(55^{\circ} \mathrm{C}\right)$ & $28: 72\left(60^{\circ} \mathrm{C}\right)$ & $\begin{array}{l}32: 68\left(30^{\circ} \mathrm{C}\right) \\
33: 67\left(40^{\circ} \mathrm{C}\right)\end{array}$ & $20: 80\left(30^{\circ} \mathrm{C}\right)$ & $23: 77\left(40^{\circ} \mathrm{C}\right)$ \\
\hline
\end{tabular}

aThe kinetic parameters of $C$. scindens DPEase are means of three replications \pm standard deviation.

${ }^{\mathrm{b}} \mathrm{NR}$, not reported.

doi:10.1371/journal.pone.0062987.t001

dialyzed against $50 \mathrm{mM}$ EDTA-free Tris-HCl buffer ( $\mathrm{pH} 7.5$ ) using a $10-\mathrm{kDa}$ cut-off membrane (Millipore). Protein concentration was determined by the method of Bradford using bovine serum albumin as a standard. SDS-PAGE was carried out according to Laemmli. Gels $(12 \% \mathrm{w} / \mathrm{v}$ polyacrylamide) were stained with Coomassie Brilliant Blue and destained with an aqueous mixture of $10 \%(\mathrm{v} / \mathrm{v})$ methanol/10\% (v/v) acetic acid.

\section{Enzyme Assay}

The activity was measured by the determination of the amount of produced D-psicose from D-fructose. The reaction mixture of $1 \mathrm{~mL}$ contained D-fructose $(50 \mathrm{~g} / \mathrm{L})$, Tris-HCl buffer (50 mM, pH 7.5), $1 \mathrm{mM} \mathrm{Mn}^{2+}$, and $1 \mu \mathrm{M}$ enzyme. The reaction was carried out at $60^{\circ} \mathrm{C}$ for $10 \mathrm{~min}$, and was terminated by boiling for $5 \mathrm{~min}$. The generated D-psicose was determined by the HPLG method. One unit of enzyme activity was defined as the amount of enzyme catalyzing the formation of $1 \mu \mathrm{mol} \mathrm{D}$-psicose per min.

\section{Effect of Temperature, $\mathrm{pH}$, and Metal lons}

The optimum temperature of enzyme activity was measured by assaying the enzyme samples over the range of $35-75^{\circ} \mathrm{C}$ for $2 \mathrm{~min}$. Two buffer systems, sodium phosphate $(50 \mathrm{mM}$, pH 5.5-7.0) and Tris-HCl (50 mM, pH 7.5-9.0), were used for measuring the optimum $\mathrm{pH}$ of enzyme activity. The thermal stability of the enzyme was studied by incubating the enzyme in Tris-HCl buffer (50 mM, pH 7.5) at various temperatures. At given time intervals, samples were withdrawn and the residual activity was measured under standard assay conditions. To determine the $\mathrm{pH}$ stability, the enzyme was incubated at $\mathrm{pH} 5.5-9.0$ at $4^{\circ} \mathrm{C}$ for up to $2 \mathrm{~h}$, and the remaining enzyme activity was measured at time intervals under standard assay conditions. To determine the effects of cations, the samples were incubated in the presence of the different divalent metal ions at $1 \mathrm{mM}: \mathrm{MnCl}_{2}, \mathrm{CoCl}_{2}, \mathrm{FeCl}_{2}, \mathrm{NiCl}_{2}$, and $\mathrm{MgCl}_{2}$, respectively.

\section{Determination of Kinetic Parameters}

Kinetic parameters of $C$. scindens DPEase were determined in $50 \mathrm{mM}$ Tris-HCl buffer ( $\mathrm{pH} 7.5$ ) containing $1 \mathrm{mM} \mathrm{Mn}^{2+}$ and Dpricose, D-fructose, or D-tagatose as the substrate from 5 to $200 \mathrm{mM}$. Kinetic parameters, such as Michaelis-Menten constant $\left(K_{\mathrm{m}}\right)$ and turnover number $\left(k_{\text {cat }}\right)$ values for substrates were obtained using the Lineweaver-Burk equation and quantification of enzyme concentration.

\section{Circular Dichroism Measurements and Protein Unfolding Analysis}

Circular dichroism (CD) measurements were carried out with a Jasco J-810 spectropolarimeter with a Peltier temperaturecontrolled cuvette holder. For thermal unfolding, protein concentration was set as $0.4 \mathrm{mg} / \mathrm{ml}$ in $50 \mathrm{mM}$ Tris- $\mathrm{HCl}$, and protein unfolding was monitored by CD ellipticity at $220 \mathrm{~nm}$ from 40 to $86^{\circ} \mathrm{C}$ at a heating rate of $1^{\circ} \mathrm{C} / \mathrm{min}$. Samples were overlaid with mineral oil and the lids of cuvette were sealed with paraffin tape to prevent evaporation. For urea-induced unfolding, protein samples $(0.5 \mathrm{mg} / \mathrm{ml}$ in $50 \mathrm{mM}$ Tris-HCl $)$ were diluted in urea $(0.32 \mathrm{mM}$ increments up to a final urea concentration between $0-6 \mathrm{M}$ ), pre-equilibrated for $2 \mathrm{~h}$ at room temperature, and the change in the folded fraction was monitored by a CD signal at $220 \mathrm{~nm}$ at $25^{\circ} \mathrm{C}$.

The ratio of denatured and total protein in the transition range, $f_{\mathrm{d}}=\left(\varepsilon_{\mathrm{N}}-\varepsilon\right) /\left(\varepsilon_{\mathrm{N}}-\varepsilon_{\mathrm{U}}\right)$, was calculated from their $\mathrm{CD}$ signal relative to the signal of the native and unfolded base line $\varepsilon_{\mathrm{N}}$ and $\varepsilon_{\mathrm{U}}$. Melting concentration $\left(T_{\mathrm{m}}\right)$ and urea mid-transition concentration $\left(C_{\mathrm{m}}\right)$ were defined as the transition mid-point of thermal and ureainduced protein unfolding, respectively.

\section{HPLC Measurements of Monosaccharides}

The concentrations of D-fructose and D-psicose were analyzed by HPLC equipped with a refractive index detector and a $\mathrm{Ca}^{2+}$ carbohydrate column (Waters Sugar-Pak 1, Waters Corp., Milford, MA, USA). The monosaccharides were separated by 

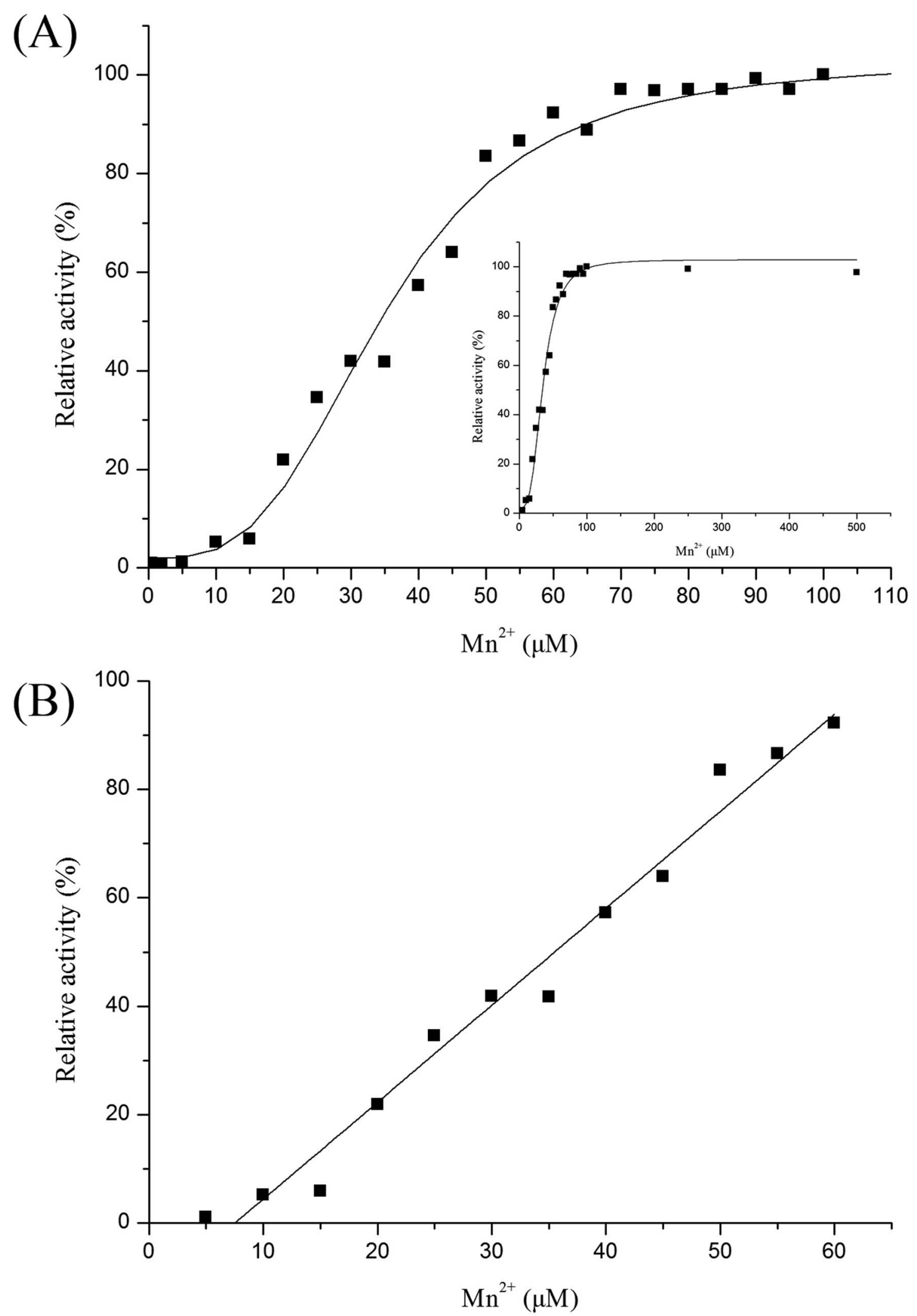

Figure 4. Effect of $\mathrm{Mn}^{2+}$ on the catalysis activity of $C$. scindens DPEase. Panel A showed the relative activities in conditions of $0-100 \mu \mathrm{M} M n^{2+}$. The curve in the inset represented the effect of $\mathrm{Mn}^{2+}$ with broad concentration range from 0 to $600 \mu \mathrm{M}$. And panel $\mathrm{B}$ represented the linear range of $\mathrm{Mn}^{2+}$ concentration effect on the enzyme activity. The experiments were developed with $1 \mu \mathrm{M} \mathrm{C}$. scindens DPEase.

doi:10.1371/journal.pone.0062987.g004 

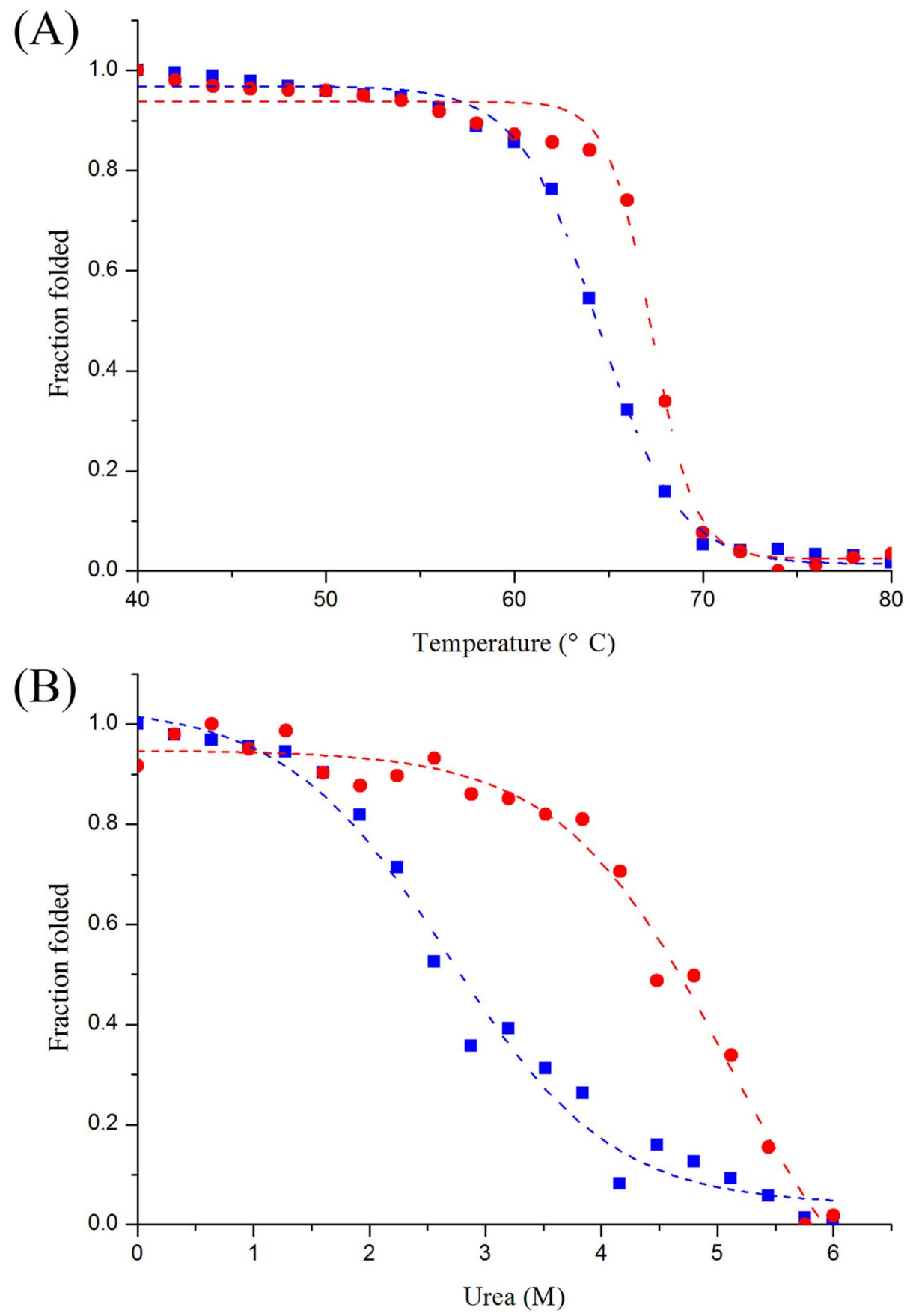

Figure 5. Thermal (A) and urea-induced (B) unfolding of $C$. scindens DPEase. The symbols $\mathbf{a}$ and represented the unfolding curves of $C$. scindens DPEase in the absence and presence of $\mathrm{Mn}^{2+}$, which were monitored by $\mathrm{CD}$. The $\mathrm{CD}$ measurements and unfolding analysis procedures were shown in Materials and Methods.

doi:10.1371/journal.pone.0062987.g005

isocratic elution in water, with column temperature at $85^{\circ} \mathrm{C}$ and flow rate at $0.4 \mathrm{~mL} / \mathrm{min}$.

\section{Results and Discussion}

\section{Amino Acid Sequence Alignment of DTEase Family Enzymes}

Compared to the reported microbial DTEase family enzymes, the DPEase from C. scindens 35704 (hypothetical protein CLOSCI_02528 with protein ID ZP_02432283) was found relatively homologous in amino acid sequence with the family enzymes from C. cellulolyticum $\mathrm{H} 10$, A. tumefaciens, Ruminococcus sp. 5_1_39BFAA, P. cichorii, and $R$. sphaeroides SK011, with 62\%, 58\%, $52 \%, 38 \%$, and $29 \%$ identity, respectively. Although the homology among the family enzymes was not high (20-60\%) in amino acid sequence, they had highly similarities in the key amino acid residues of active sites, metal coordinating sites and substrate combinant binding sites (Fig. 1). From the known structure information of A. tumefaciens DPEase [17], P. cichorii DTEase [18], and C. cellulolyticum DPEase [19], the metal coordinating sites were 
predicted consisting of Glu149, Asp182, His208, and Glu243 in C. scindens DPEase, and were strictly conserved in all DTEase family enzymes. The amino acid residues Glu156, His186, and Arg215, which were responsible for the interaction between the enzyme and $\mathrm{O} 1, \mathrm{O} 2$, and $\mathrm{O} 3$ of substrate, were also conserved in the family enzymes. However, interestingly, as for the residues providing a hydrophobic environment around the substrate, which consisted of Tyr6, Try14, Gly65, Ala107, and Phe245, C. scindens DPEase showed absolute identity with all reported DPEases, but was significantly different with the DTEases (Fig. 1). It was probably caused by the substrate binding sites composed by different amino acid residues in the structure.

\section{Cloning, Expression, and Purification of C. scindens DPEase}

The C. scindens 35704 genomic sequence was completed and deposited as GenBank accession number NZ_DS499706. According to the genome sequencing, the nucleotide sequence of the gene coding hypothetical protein CLOSCI_02528 (characterized as DPEase) was given as Gene ID 167760156. This DPEase-coding gene was obtained by the full-length gene synthesis, instead of the PCR amplification in vitro using genome as DNA template. The coding gene sequence was intentionally incorporated with $\mathcal{N} d e \mathrm{I}$ and $X h_{0} \mathrm{I}$ sites in the $5^{\prime}$ - and $3^{\prime}$-terminal of the gene, respectively, and then was cloned into pET-22b(+) vector with $\mathcal{N} d e \mathrm{I}$ and XhoI sites, therefore, an in-frame fusion $6 \times$ histidine-tag sequence at the G-terminus was provided in the reconstructed plasmid, named by pET-cs-dpe. This allowed for a generic single step purification of the recombinant DPEase using nickel-affinity column chromatography.

The pET-cs-dpe was then introduced into the expression host, E. coli BL21(DE3), to overexpress DPEase by IPTG induction. SDS-PAGE analyses on the extracts of $E$. coli BL21(DE3) harboring pET-Csc-dpe induced by IPTG revealed the presence of large amounts of protein around $31 \mathrm{kDa}$, compared to that of the control E. coli BL21(DE3) cells harboring plasmid pET-22b(+); and the molecular weight was in agreement with the predicted molecular mass for the DPEase protein, suggesting the DPEase was overexpressed by IPTG induction (Fig. 2A). After IPTG induction, the $E$. coli cells were harvested by centrifugation and disrupted by sonification. Cell debris was removed by centrifugation at $4^{\circ} \mathrm{C}$ and $20,000 \mathrm{~g}$ for $20 \mathrm{~min}$. The supernatant was subjected to the $\mathrm{Ni}^{2+}$-Chelating Sepharose Fast Flow affinity column, and the recombinant DPEase fused by C-terminal $6 \times$ histidine-tag was purified to electrophoretic homogeneity with a single band on SDS-PAGE (Fig. 2B). The molecular weight of the purified $C$. scindens DPEase was estimated to be approximately $32 \mathrm{kDa}$ by SDS-PAGE, however, the gel filtration experiment data showed the molecular weight of native enzyme was approximately $125 \mathrm{kDa}$, suggesting the enzyme was a tetramer with four identical subunits. The tetramer manner of subunits assembly was also characterized in other DTEase family enzymes, such as A. tumefaciens DPEase [13], C. cellulolyticum DPEase [15], and Ruminococcus sp. DPEase [19]; however, the R. sphaeroides SK011 DTEase [14] and $P$. cichorii DTEase were determined as dimers [21].

\section{Effects of Temperature and $\mathrm{pH}$ on $C$. scindens DPEase}

The temperature and $\mathrm{pH}$ profiles for $C$. scindens DPEase activity were shown in Fig. $3 \mathrm{~A}$ and $3 \mathrm{~B}$, respectively. The enzyme activity

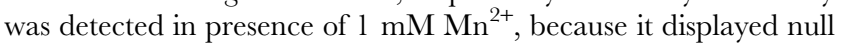
activity without metal ions. The optimum temperature and $\mathrm{pH}$ for enzyme activity are 7.5 and $60^{\circ} \mathrm{C}$. Comparison of biochemical properties of $C$. scindens DPEase and other reported DTEase family enzymes was shown in Table 1 . The optimum temperature of the known DTEase family enzymes is the range of $40-60^{\circ} \mathrm{C}$ and the optimum $\mathrm{pH}$ is all weakly alkaline ranged from 7.5 to 9.0.

C. scindens DPEase retained 95 and $86 \%$ of its initial activity after $2 \mathrm{~h}$ of exposure at 40 and $45^{\circ} \mathrm{C}$ (Fig. 3C), which indicated that the enzyme was relatively stable below $50^{\circ} \mathrm{C}$. The half-life of the enzyme at $50^{\circ} \mathrm{C}$ was approximately $108 \mathrm{~min}$, which was longer than that of, A. tumefaciens DPEase (63.5 min) [13] and $P$. cichorii DTEase (approximately $60 \mathrm{~min}$ ) [20], but shorter than that of C. cellulolyticum DPEase [15] and Ruminococcus sp. DPEase [16]. Like other wild DTEase family enzymes, C. scindens DPEase was easily deactivated under exposure at higher temperatures of more than $55^{\circ} \mathrm{C}$. When incubated at $60^{\circ} \mathrm{C}$, the half-life of $C$. scindens DPEase was around $50 \mathrm{~min}$, which was shorter than that of Ruminococcus sp. DPEase (1.6 h) [16], but longer than other wild DTEase family enzymes. In addition, more than $80 \%$ activity of the purified $C$. scindens DPEase was retained $\mathrm{pH}$ 6.0-9.0 after incubation at $4^{\circ} \mathrm{C}$ for $2 \mathrm{~h}$ (Fig. 3D), indicating that the C. scindens DPEase was relatively stable under neutral and weakly alkaline conditions.

Thermostability is an important property of DTEase family enzymes to realize the industrial enzymatic production of Dpsicose. Some DTEase family enzymes could be more thermostable in presence of metal ion cofactor, such as C. cellulolyticum DPEase [15] and Ruminococcus sp. DPEase [16]. The thermostability also could be improved through the molecular modification. Choi et al. constructed the I33L S213C double-site variant of $A$. tumefaciens DPEase, and the variant enzyme showed significant increases in optimal temperature, half-life, and melting temperature, compared with the wild-type enzyme; and the variant enzyme's half-life at $50^{\circ} \mathrm{C}$ reached $1,853 \mathrm{~min}$, which was 29.9-fold of that of the wild-type enzyme [22].

\section{Effects of Metal lons on C. scindens DPEase Activity}

C. scindens DPEase displayed null activity in absence of metal ion, and only had catalysis activity when adding divalent metal ion. Also, even in presence of metal ion, the enzyme would lose all activity when adding EDTA as metal ion chelating agent. Therefore, the C. scindens DPEase was a kind of strictly metaldependent enzyme, which is similar to C. cellulolyticum DPEase, but different with other DTEase family enzymes [15].

To investigate the effect of metal ions, the relative activity of $C$. scindens DPEase was detected in presence of different divalent metal ions, which were added at the final concentration of $1 \mathrm{mM}$. C. scindens DPEase showed a maximal activity in the presence of $\mathrm{Mn}^{2+}$; however, when $\mathrm{Mn}^{2+}$ was replaced with $\mathrm{Co}^{2+}, \mathrm{Fe}^{2+}, \mathrm{Ni}^{2+}$, and $\mathrm{Mg}^{2+}$, the enzyme activity was reduced to $92 \%, 70 \%, 69 \%$, and $41 \%$ of that in presence of $\mathrm{Mn}^{2+}$, respectively. By comparison, C. cellulolyticum DPEase is also metal-dependent but with optimum metal ion of $\mathrm{Co}^{2+}$ [15]; P. cichorii DTEase does not require any cofactor for its activity [20]; Ruminococcus sp. DPEase [16], A. tumefaciens DPEase [13], and R. sphaeroides DTEase [14] can display activity without metal ion, but their activity is significantly enhanced by metal ions especially $\mathrm{Mn}^{2+}$ or $\mathrm{Co}^{2+}$.

In addition, the effect of metal cofactor concentration on catalytic activity of metal-dependent DPEase was also investigated. The $\mathrm{Mn}^{2+}$ concentration titration on catalytic activity with $1 \mu \mathrm{M}$ C. scindens DPEase was developed, and the overall results of the $\mathrm{Mn}^{2+}$ concentration effect on activity was like S-curve, and different with general first order reaction model (Fig. 4A). The activity could not be detected when the $\mathrm{Mn}^{2+}$ concentration was below $5 \mu \mathrm{M}$, probably because the enzyme needed a certain amount of $\mathrm{Mn}^{2+}$ concentration to effectively bind the metal cofactor. Then, the relative activity increased linearly with the 
addition of metal ion with between 5 and $60 \mu \mathrm{M}$, which accorded with first order reaction (Fig. 4B). When the $\mathrm{Mn}^{2+}$ concentration was more than $60 \mu \mathrm{M}$, the relative activity tended to be stationary, probably because the binding of enzyme to metal ion was close to saturation (Fig. 4A). The similar result was reported on another metal-dependent enzyme, Geobacillus stearothermophilus L-arabinose isomerase, which also displayed null activity without metal ions, but rapidly restored catalytic activity by adding trace amount of $\mathrm{Mn}^{2+}$ [23]. Interestingly, for aldose isomerase or ketose epimerase having metal coordinating region in structure, some enzyme are metal-dependent and must require metal cofactor to display activity $[15,23,24]$; some not only do not require metal ions but also could not be activated by metal ions [20,25,26]; and other could display catalytic activity without metal ion, however, their activity could be remarkably enhanced by metal ions $[13,14,16]$. The mechanism of different metal independence of these enzymes having metal coordinating region may be fascinating topic worthy of deep investigation.

\section{Effects of $\mathrm{Mn}^{2+}$ on Structural Stability of $C$. scindens DPEase}

To study the effect of $\mathrm{Mn}^{2+}$ on thermostability based on the structural aspects, thermal unfoldings of both enzymes in the absence and the presence of $\mathrm{Mn}^{2+}$ were performed using CD. Shown in Fig. 5A, metal-free C. scindens DPEase had the apparent melting temperature $\left(T_{\mathrm{m}}\right)$ of $64.4^{\circ} \mathrm{C}$, whereas the metal-bound enzyme showed higher $T_{\mathrm{m}}$ of $67.3^{\circ} \mathrm{C}$. Therefore, it was suggested that the metal ion was important for $C$. scindens DPEase with respect to the unfolding and structural stability during thermal denaturation. Similar result about the improvement effect of metal ion on the thermostability was reported on the metal-dependent $G$. stearothermophilus L-arabinose isomerase, in which the $T_{\mathrm{m}}$ of metalbound enzyme was $6^{\circ} \mathrm{C}$ higher than that of the metal-free enzyme [23].

In addition to the thermal unfolding, the urea-induced unfoldings of both metal-free and metal-bound $C$. scindens DPEases were also studied using CD. According to the urea-induced denaturation curves (Fig. 5B), the urea midtransition concentration $\left(C_{\mathrm{m}}\right)$ was derived, and the $C_{\mathrm{m}}$ of metal-bound $C$. scindens DPEase $(5.09 \mathrm{M})$ was much higher than that of metal-free enzyme $(2.68 \mathrm{M})$, suggesting that the metal ion effectively improved the structural stability of enzyme against the protein denaturant urea. Therefore, the metal ion not only was the essential cofactor for $C$. scindens DPEase to have the catalysis activity, but also could improve the structural stability during both heat- and ureainduced unfolding.

\section{References}

1. Oshima H, Kimura I, Izumori K (2006) Psicose contents in various food products and its origin. Food Sci Technol Res 12: 137-143.

2. Mu W, Zhang W, Feng Y, Jiang B, Zhou L (2012) Recent advances on applications and biotechnological production of D-psicose. Appl Microbiol Biotechnol 94: 1461-1467.

3. Hayashi N, Iida T, Yamada T, Okuma K, Takehara I, et al. (2010) Study on the postprandial blood glucose suppression effect of D-psicose in borderline diabetes and the safety of long-term ingestion by normal human subjects. Biosci Biotechnol Biochem 74: 510-519.

4. Iida T, Kishimoto Y, Yoshikawa Y, Hayashi N, Okuma K, et al. (2008) Acute $\mathrm{D}$-psicose administration decreases the glycemic responses to an oral maltodextrin tolerance test in normal adults. J Nutr Sci Vitaminol (Tokyo) 54: $511-514$.

5. Suna S, Yamaguchi F, Kimura S, Tokuda M, Jitsunari F (2007) Preventive effect of D-psicose, one of rare ketohexoses, on di-(2-ethylhexyl) phthalate (DEHP)induced testicular injury in rat. Toxicol Lett 173: 107-117.

\section{Substrate Specificity, Enzyme Kinetics, and Equilibrium Ratio}

The optimum substrate of C. scindens DPEase was D-psicose, and the substrate specificity decreased in the following order: Dfructose, D-tagatose, and D-sorbose. As other known DTEase family enzymes, $C$. scindens DPEase could not catalyze D-fructose6-phosphate or D-ribulose-5-phosphate. C. scindens DPEase had the similar substrate specificity with Ruminococcus sp. DPEase [16], C. cellulolyticum DPEase [14], and A. tumefaciens DPEase [13], showing the optimum substrate of D-psicose; however, the optimum substrate of $P$. cichorii DTEase [20] and $R$. sphaeroides DTEase [14] was D-tagatose and D-fructose, respectively.

The Michaelis-Menten constant $\left(K_{\mathrm{m}}\right)$, turnover number $\left(k_{\mathrm{cat}}\right)$, and catalytic efficiency $\left(k_{\text {cat }} / K_{\mathrm{m}}\right)$ values of $C$. scindens DPEase for substrate D-psicose were estimated to be $28.3 \mathrm{mM}, 1826.8 \mathrm{~min}^{-1}$, and $64.5 \mathrm{mM}^{-1} \mathrm{~min}^{-1}$, respectively. And the $k_{\text {cat }} / K_{\mathrm{m}}$ for Dpsicose was much higher than that for other substrates, and was 7.4-fold and 258-fold of that for D-fructose and D-tagatose, respectively. These data are very similar to those of Ruminococcus sp. DPEase [16], C. cellulolyticum [15] and A. tumefaciens DPEases [13], showing these four DPEases had the same substrate specificity (Table 1).

The equilibrium ratio between D-psicose and D-fructose of $C$. scindens DPEase was measured to be 28:72, which was higher than that of P. cichorii DTEase (20:80) [20] and $R$. sphaeroides DTEase (23:77) [14], but lower than that of C. cellulolyticum DPEase (32:68) [15] and A. tumefaciens DPEase (33:67) [13] (Table 1). In addition, C. scindens DPEase could epimerize D-tagatose into D-sorbose, with the turnover ratio of $8.6 \%$.

In conclusion, the noncharacterized gene CLOSCI_02528 from C. scindens ATCG 35704, encoding the hypothetical protein ZP_02432283, was cloned and expressed in E. coli, and the protein was characterized as a member of DTEase family enzymes with the optimum substrate of D-psicose. The enzyme showed maximum activity at $\mathrm{pH} 7.5$ and $60^{\circ} \mathrm{C}$. It was strictly metaldependent and required $\mathrm{Mn}^{2+}$ as optimum cofactor for activity. In addition, $\mathrm{Mn}^{2+}$ improved the structural stability during both thermal and urea-induced unfolding. The $k_{\text {cat }} / K_{\mathrm{m}}$ for D-psicose and D-fructose was estimated to be 64.5 and $8.72 \mathrm{mM}^{-1} \mathrm{~min}^{-1}$, respectively. The equilibrium ratio between D-psicose and Dfructose of the enzyme was 28:72.

\section{Author Contributions}

Conceived and designed the experiments: WZ QX LZ BJ WM. Performed the experiments: WZ DF QX. Analyzed the data: WZ QX WM. Contributed reagents/materials/analysis tools: DF QX LZ BJ. Wrote the paper: QX WM.

6. Murata A, Sekiya K, Watanabe Y, Yamaguchi F, Hatano N, et al. (2003) A novel inhibitory effect of $\mathrm{D}$-allose on production of reactive oxygen species from neutrophils. J Biosci Bioeng 96: 89-91.

7. Takata MK, Yamaguchi F, Nakanose K, Watanabe Y, Hatano N, et al. (2005) Neuroprotective effect of D-psicose on 6-hydroxydopamine-induced apoptosis in rat pheochromocytoma (PC12) cells. J Biosci Bioeng 100: 511-516.

8. Sun Y, Hayakawa S, Ogawa M, Izumori K (2005) Evaluation of the site specific protein glycation and antioxidant capacity of rare sugar-protein/peptide conjugates. J Agric Food Chem 53: 10205-10212.

9. Sun Y, Hayakawa S, Izumori K (2004) Modification of ovalbumin with a rare ketohexose through the Maillard reaction: effect on protein structure and gel properties. J Agric Food Chem 52: 1293-1299.

10. Izumori K, Khan AR, Okaya H, Tsumura T (1993) A new enzyme, Dketohexose 3-epimerase, from Pseudomonas sp. ST-24. Biosci Biotechnol Biochem 57: 1037-1039.

11. Itoh H, Sato T, Izumori K (1995) Preparation of D-psicose from D-fructose by immobilized D-tagatose 3-epimerase. J Ferment Bioeng 80: 101-103. 
12. Takeshita K, Suga A, Takada G, Izumori K (2000) Mass production of Dpsicose from d-fructose by a continuous bioreactor system using immobilized Dtagatose 3-epimerase. J Biosci Bioeng 90: 453-455.

13. Kim HJ, Hyun EK, Kim YS, Lee YJ, Oh DK (2006) Characterization of an Agrobacterium tumefaciens D-psicose 3-epimerase that converts D-fructose to Dpsicose. Appl Environ Microbiol 72: 981-985.

14. Zhang L, Mu W, Jiang B, Zhang T (2009) Characterization of D-tagatose-3epimerase from Rhodobacter sphaeroides that converts D-fructose into D-psicose. Biotechnol Lett 31: 857-862.

15. Mu W, Chu F, Xing Q Yu S, Zhou L, et al. (2011) Cloning, expression, and characterization of a D-psicose 3-epimerase from Clostridium cellulolyticum H10. J Agric Food Chem 59: 7785-7792.

16. Zhu Y, Men Y, Bai W, Li X, Zhang L, et al. (2012) Overexpression of D-psicose 3-epimerase from Ruminococcus sp. in Escherichia coli and its potential application in D-psicose production. Biotechnol Lett 34: 1901-1906.

17. Kim K, Kim HJ, Oh DK, Cha SS, Rhee S (2006) Crystal structure of D-psicose 3-epimerase from Agrobacterium tumefaciens and its complex with true substrate Dfructose: a pivotal role of metal in catalysis, an active site for the nonphosphorylated substrate, and its conformational changes. J Mol Biol 361: 920 931.

18. Yoshida H, Yamada M, Nishitani T, Takada G, Izumori K, et al. (2007) Crystal structures of $\mathrm{D}$-tagatose 3-epimerase from Pseudomonas cichorii and its complexes with D-tagatose and D-fructose. J Mol Biol 374: 443-453.
19. Chan HC, Zhu Y, Hu Y, Ko TP, Huang CH, et al. (2012) Crystal structures of D-psicose 3-epimerase from Clostridium cellulolyticum $\mathrm{H} 10$ and its complex with ketohexose sugars. Protein Cell 3: 123-131.

20. Itoh H, Okaya H, Khan AR, Tajima S, Hayakawa S, et al. (1994) Purification and characterization of D-tagatose 3-epimerase from Pseudomonas sp. ST-24. Biosci Biotechnol Biochem 58: 2168-2171.

21. Ishida Y, Kamiya T, Itoh H, Kimura Y, Izumori K (1997) Cloning and characterization of the D-tagatose 3-epimerase gene from Pseudomonas cichorii ST24. J Ferment Bioeng 83: 529-534.

22. Choi JG, Ju YH, Yeom SJ, Oh DK (2011) Improvement in the thermostability of D-psicose 3-epimerase from Agrobacterium tumefaciens by random and sitedirected mutagenesis. Appl Environ Microbiol 77: 7316-7320.

23. Lee DW, Choe EA, Kim SB, Eom SH, Hong YH, et al. (2005) Distinct metal dependence for catalytic and structural functions in the l-arabinose isomerases from the mesophilic Bacillus halodurans and the thermophilic Geobacillus stearothermophilus. Arch Biochem Biophys 434: 333-343.

24. Lin CJ, Tseng WC, Lin TH, Liu SM, Tzou WS, et al. (2010) Characterization of a thermophilic L-rhamnose isomerase from Thermoanaerobacterium saccharolyticum NTOU1. J Agric Food Chem 58: 10431-10436.

25. Rhimi M, Bejar S (2006) Cloning, purification and biochemical characterization of metallic-ions independent and thermoactive l-arabinose isomerase from the Bacillus stearothermophilus US100 strain. Biochim Biophys Acta 1760: 191-199.

26. Park CS, Yeom SJ, Kim HJ, Lee SH, Lee JK, et al. (2007) Characterization of ribose-5-phosphate isomerase of Clostridium thermocellum producing D-allose from D-psicose. Biotechnol Lett 29: 1387-1391. 